\title{
Erratum to: Donald and Winston at the Ministry of Alternative Facts
}

\author{
John Rodden ${ }^{1}$
}

Published online: 22 May 2017

(C) Springer Science+Business Media New York 2017

\section{Erratum to: Soc}

DOI 10.1007/s12115-017-0127-8

The publisher regrets not having performed the following corrections requested by the Editor at the proof stage of the article.

In the keywords, five book titles are not in italics: Nineteen Eighty-Four, The Art of the Deal, Animal Farm, The Handmaid's Tale.

On the second page, right column, first full paragraph, line six, a word is missing at the end of the line: "went viral and has been" ("been" is missing).

Also on the second page, second full paragraph, line five, two words are missing at the end of the line: "In Britain, sales of the" ("sales of" is missing).

Same page, footnote 1, second to last full paragraph, delete comma after Of Mice and Men.

On the third page, left column, there should be a hyphen, not a dash, after Mein Kampf.

Also on the third page, right column, first full paragraph, delete comma after "A.D.D. culture".

The online version of the original article can be found at http://dx.doi:10. 1007/s12115-017-0127-8

John Rodden

jgrodden1@gmail.com

1118 Beautybush Trail, Georgetown, TX 78628, USA 